\title{
Asthma
}

\section{Fact Sheet}

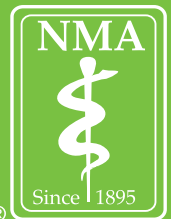

National Medical Association

8403 Colesville Road, Suite 920, Silver Spring, MD 20910

http://asthma.nmanet.org/

www.NMAnet.org

202-347-1895

202-347-0722 (FAX)

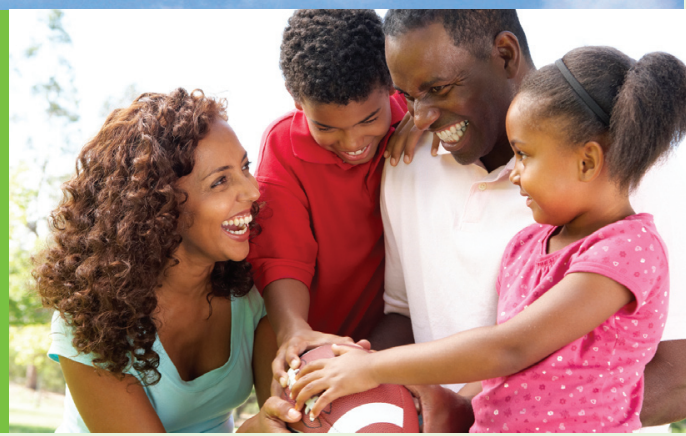

\section{What is Asthma?}

Asthma is a chronic inflammation of the airways in the lungs. The inflammation causes the airways to swell, tighten, and narrow. When this happens breathing becomes difficult. The most common asthma symptom is frequent coughing, especially at night or after exercise. Other asthma symptoms include shortness of breath, chest tightness, and wheezing.

\section{Who Gets Asthma?}

Nearly 25 million Americans currently have asthma. ${ }^{3}$ Asthma is the most common chronic childhood disease, affecting about 1 child in every $10 .{ }^{4}$ The disease affects people of any race, age or gender. African Americans have the most difficulty, particularly women and children. ${ }^{5}$ Currently, 4 million African Americans have asthma. ${ }^{6}$ No one knows exactly why some people get asthma and others do not. Medical researchers have found that having a family member who has allergies or asthma, or being exposed to certain things in the environment, can increase the chance a person will develop asthma. ${ }^{1}$

\section{Things that Cause Asthma. Attacks:}

Asthma triggers, including irritants and allergens, can bring on an asthma attack by making your airways more swollen and inflamed and by causing the muscles around your airways to tighten. Allergens cause an allergic reaction that can trigger an asthma attack. Irritants from the environment can also irritate your lungs. Other things, like having the cold or flu, can trigger asthma attacks too. Different people have different asthma triggers. Talk with your doctor about what makes your asthma worse. Then decide with your doctor what to do to manage your triggers.

\section{IRRITANTS}

(things in the environment that irritate airways)

Tobacco smoke

Other smoke (kerosene heater, fireplace)

Strong odors and sprays (cleaning products, unvented gas stove, perfume, hair spray)

\section{ALLERGENS}

(things that cause an allergic reaction)

Animal dander (cats, dogs)

Dust mites

Cockroaches

Pollen (grass, tree, ragweed)

Indoor mold

Outdoor mold
OTHER ASTHMA TRIGGERS (more things that can make asthma worse)

Exercise or physical activity

Viral infections (colds, flu)

Sinusitis (sinus infection)

Some medications

Sulfites in foods (shrimp, dried fruit, processed potatoes)

Weather changes (cold air) 


\section{How to Manage Asthma}

Using an inhaler for the quick-relief of asthma symptoms is not enough. Don't put up with asthma symptoms. Take these four steps with your doctor to control your asthma.

1. Use inhaled corticosteroids. Most people with asthma need to take inhaled corticosteroids every day to reduce airway inflammation and prevent asthma symptoms. Ask your doctor, nurse, pharmacist, or asthma educator to show you how to use all of your medications the right way, so they can work better.

2. Ask your doctor for a written asthma action plan. Your written asthma action plan will remind you what to do every day to prevent asthma symptoms. It also will tell you what to do if an asthma attack happens. Be prepared to respond quickly to the warning signs of an asthma attack. Share copies of the written asthma action plan with family members, caregivers, and others who can help, such as school nurses.
3. Schedule follow-up visits. Asthma can change over time. See your doctor at least every six months-or more often if needed. The doctor will assess your asthma severity (how bad your asthma is) at the first visit to determine how to treat your asthma. He or she will check your asthma control at each follow-up visit and change your treatment if needed.

4. Control environmental exposures. Exposure to your asthma triggers can lead to an asthma attack. Know your triggers and learn how to avoid or manage them.

\section{Asthma In African Americans:}

- African-Americans are hospitalized because of asthma three and one-half times more than whites. ${ }^{4}$

- African-American children are three times more likely than Caucasians to die from asthma. ${ }^{4}$

$\square$ Most African American children do not use an asthma management action plan. ${ }^{5}$

- Over 4 million African Americans have asthma. ${ }^{6}$

African American women have the highest asthma mortality rate out of all racial groups. ${ }^{4}$

Black children have a $500 \%$ higher death rate and a $250 \%$ hospital rate compared to non-Hispanic white children. ${ }^{14}$

- Compared to non-Hispanic whites, African American children had a death rate 7 times higher. ${ }^{14}$

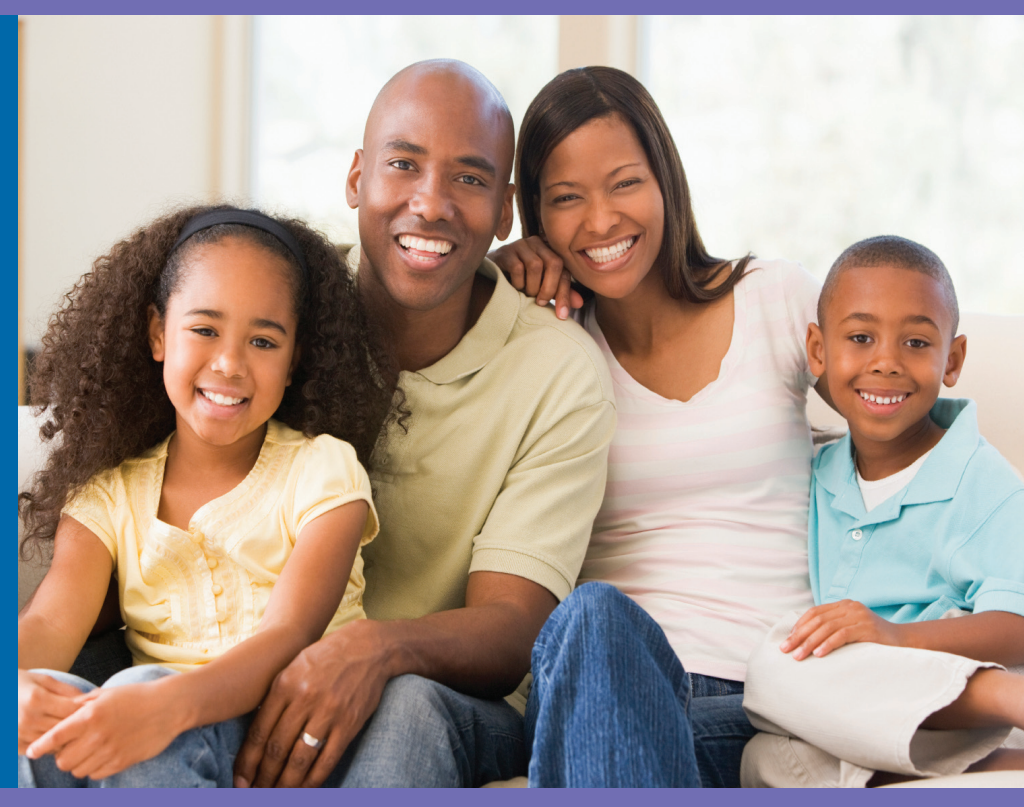

\section{References:}

1. National Medical Association Asthma Website: What is Asthma? Available at http://www.nmaasthmanet.org/patients1.htm

2. Asthma and Allergy Foundation of America: Asthma Overview. Available at $\mathrm{http}: / /$ www. aafa. org/display.cfm?id=8\&cont=5

3. Centers for Disease Control and Prevention. FastStats: Asthma: Available at http://www.cdc.gov/nchs/fastats/asthma.htm

4. Bloom B, CohenRA, Freeman G. Summary health statistics for U.S. children: National Health Interview Survey, 2009. National Center for Health Statistics Vital Health Stat 10(247). 2010. Available at http://www.cdc.gov/nchs/data/series/ sr_10/sr10_247.pdf

5. American Lung Association. State of Lung Disease in Diverse Communities 2010: Asthma. Available at http://www.lungusa.org/assets/documents/publications/ solddc-chapters/asthma.pdf

6. U.S. Department of Health and Human Services. Centers for Disease Control and Prevention. National Center for Health Statistics. National Health Interview Survey, 2009. Available at http://www.cdc.gov/nchs/fastats/asthma.htm

7. WebMD: Asthma Causes and Triggers. Available at http://www.webmd.com/ asthma/guide/asthma-triggers

8. Centers for Disease Control and Prevention. Asthma: Important Asthma Triggers. Available at http://www.cdc.gov/asthma/triggers.html

9. National Medical Association Asthma Website: What Causes An Attack? Available at http://www.nmaasthmanet.org/patients2.htm

10. U.S. Department of Health and Human Services. National Institutes of Health. National Heart, Blood and Lung Institute: Asthma Action Plan. Available at http://www.nhlbi.nih.gov/health/public/lung/asthma/asthma_actplan.pdf

11. National Heart, Lung and Blood Institute. National Asthma Control Initiative. Patient Families and Caregivers. Available at http://www.nhlbi.nih.gov/health/prof/lung/ asthma/naci/audiences/patients-families.htm

12. National Medical Association Asthma Website: Asthma Care and Treatment Available at http://www.nmaasthmanet.org/patients4.htm

13. U.S. Department of Health and Human Services. National Institutes of Health. National Heart, Lung and Blood Institute. Putting Guidelines Implementation Panel Report in Motion: A Plan of Action for the National Asthma Control Initiative. Available at http://www.nhlbi.nih.gov/health/prof/lung/asthma/naci/pubs/ naci-plan-of-action.pdf

14. U.S. Department of Health and Human Services. The Office of Minority Health Asthma and African Americans. Available at http://minorityhealth.hhs.gov/ templates/content.aspx?ID=6170

This fact sheet was funded in part by the National Asthma Control Initiative of the National Heart, Lung, and Blood Institute (NHLBI), National Institutes of Health (NIH). 